\title{
Residencia pedagógica en IFRN: prácticas de lectura literaria en clases de español en escuela pública
}

\author{
Mariana Carla Augusto de Lima \\ marianacarla.lima@live.com \\ https://orcid.org/0000-0002-7113-9291 \\ Instituto Federal de Educação, Ciência e Tecnologia do Rio Grande do Norte (IFRN) \\ Natal, Brasil \\ Girlene Moreira da Silva \\ girlene.moreira@ifrn.edu.br \\ https://orcid.org/0000-0002-2936-1753 \\ Instituto Federal de Educação, Ciência e Tecnologia do Rio Grande do Norte (IFRN) \\ Natal, Brasil
}

Recibido: 26/03/2021 Aceptado: 30/09/2021

\section{Resumen}

Este artículo forma parte de una investigación realizada en 2019 y cuyo objetivo fue presentar y aplicar propuestas didácticas con lectura literaria en lengua española en clases de secundaria de una escuela pública. Presentamos reflexiones, así como prácticas pedagógicas desarrolladas, enfocadas en la importancia y efectividad pedagógica de la literatura en las clases de español, vinculadas al programa de Residencia Pedagógica en Lengua Española del Instituto Federal de Educación, Ciencia y Tecnología de Rio Grande do Norte (IFRN). El estudio se centró en propuestas de intervención en un caso y contexto específicos, con ganas a contribuir al crecimiento de las asignaturas (estudiantes de secundaria de una escuela pública donde trabajamos como becarios en el programa de residencia pedagógica). Optamos por utilizar el método hipotético-deductivo. Las clases se produjeron a partir del estudio y las directrices de autores como Mendoza (2007), Albaladejo (2007), Silva (2011, 2016), Cosson (2014), Acquaroni (2007), entre otros. Al final de la investigación, logramos nuestros objetivos, desarrollando y aplicando propuestas didácticas con textos literarios para las clases de español en una escuela pública participante en el proyecto de Residencia Pedagógica IFRN con el fin de integrar y brindar al estudiante su desarrollo en más de una habilidad lingüística.

Palabras clave: Texto literario. Lengua Española. Propuestas pedagógicas. Residencia pedagógica.

\section{A residência pedagógica no IFRN: práticas de leitura literária em aulas de língua espanhola na escola pública}

\begin{abstract}
Resumo
Este artigo é parte de uma pesquisa realizada em 2019 e teve como objetivo apresentar e aplicar propostas didáticas com a leitura literária em língua espanhola em aulas do ensino médio de uma escola pública. Apresentamos reflexões, bem como práticas pedagógicas desenvolvidas, voltadas para a importância e a eficácia pedagógica da literatura em aulas de espanhol, vinculadas ao programa Residência Pedagógica de Língua Espanhola do Instituto Federal de
\end{abstract}


Educação, Ciência e Tecnologia do Rio Grande do Norte (IFRN). O estudo se voltou para propostas de intervenção em um caso e um contexto específico, tendo em vista contribuir com o crescimento dos sujeitos (alunos do ensino médio de uma escola pública em que atuamos como bolsistas do programa residência pedagógica). Optamos por utilizar o método hipotéticodedutivo. As aulas foram produzidas a partir do estudo e das orientações de autores como Mendoza (2007), Albaladejo (2007), Silva (2011, 2016), Cosson (2014), Acquaroni (2007), entre outros. Ao final da pesquisa alcançamos nossos objetivos, desenvolvendo e aplicando propostas didáticas com textos literários para aulas de espanhol em uma escola pública participante do projeto Residência Pedagógica do IFRN de maneira a integrar e a proporcionar ao aluno o seu desenvolvimento em mais de uma habilidade linguística.

Palavras chave: Texto literário. Língua Espanhola. Propostas pedagógicas. Residência pedagógica.

\title{
Pedagogical residence at IFRN: literary reading practices in Spanish language classes in public school
}

\begin{abstract}
This article is part of a research conducted in 2019 and aimed to present and apply didactic proposals with literary reading in Spanish in high school classes at a public school. We present reflections, as well as developed pedagogical practices, focused on the importance and pedagogical effectiveness of literature in Spanish classes, linked to the Spanish Language Pedagogical Residency program of the Federal Institute of Education, Science and Technology of Rio Grande do Norte (IFRN). The study turned to intervention proposals in a specific case and context, with a view to contributing to the growth of the subjects (high school students from a public school where we work as scholars in the pedagogical residency program). We chose to use the hypothetical-deductive method. The classes were produced from the study and the guidelines of authors such as Mendoza (2007), Albaladejo (2007), Silva (2011, 2016), Cosson (2014), Acquaroni (2007), among others. At the end of the research, we achieved our goals, developing and applying didactic proposals with literary texts for Spanish language classes in a public school participating in the IFRN Pedagogical Residence project to integrate and provide the student with his development in more than one linguistic skill.
\end{abstract}

Keywords: Literary text. Spanish Language. Pedagogical proposals. Pedagogical residence.

\section{Introdução}

A partir da nossa experiência como bolsistas no Programa Institucional de Bolsa de Iniciação à Docência (PIBID) e no programa Residência Pedagógica da Coordenação de Aperfeiçoamento de Pessoal de Nível Superior (CAPES), em que tivemos contato com alunos do ensino médio de escolas públicas durante três anos, observamos que a realidade dos professores de língua estrangeira nas escolas públicas do Rio Grande do Norte é bastante desafiadora e árdua, principalmente pelo fato de possuírem uma carga horária semanal muito reduzida. 
Participamos do programa Residência Pedagógica no Instituto Federal de Educação, Ciência e Tecnologia do Rio Grande do Norte (IFRN), Campus Natal Central como bolsistas e atuamos na Escola Estadual Senador Dinarte Matriz, localizada no bairro periférico de Mãe Luíza na cidade do Natal, Rio Grande do Norte (RN). O presente trabalho é parte de uma pesquisa realizada em 2019, em que decidimos realizar nossa investigação propondo e aplicando aulas com o tratamento didático do texto literário com a finalidade de mostrar possibilidades de se trabalhar a leitura literária nas aulas de ensino médio e de contribuir para a formação leitora dos alunos desta modalidade no que concerne à Língua Espanhola. Parte da regência foi realizada através de oficinas de língua espanhola com o objetivo de realizar um maior contato dos alunos com a língua espanhola, em especial, através da leitura literária com abordagem de diferentes temas e com a realização de atividades diversas.

Estamos cientes de que o desenvolvimento da compreensão leitora de alunos de línguas têm sido uma preocupação em qualquer sociedade que veja, na educação, um instrumento de ascensão social do indivíduo, de ampliação de conhecimento, bem como do desenvolvimento de organização social. Trabalhar a leitura é um desafio na prática docente e, quando falamos em literatura, o desafio se configura ainda maior, principalmente no âmbito da língua estrangeira. Segundo Silva (2016), as dificuldades vão desde os horários destinados à disciplina, que são poucos para um trabalho mais profundo, até os receios enfrentados pelo docente no trabalho com a literatura, devido, em muitos casos, a sua pouca ou nenhuma preparação acadêmica para a sistematização do tratamento didático da literatura.

Conscientes, assim como Silva (2016), de que a literatura contribui para o desenvolvimento da competência leitora e literária, bem como ajuda na formação de um leitor crítico, como também favorece a formação de um pensamento a respeito de questões éticas, políticas, sociais e ideológicas, realizamos este estudo, cujo objetivo geral foi elaborar propostas didáticas para o uso do texto literário em oficinas de Espanhol como língua estrangeira (E/LE) para alunos do ensino médio e do fundamental, vinculadas ao programa Residência Pedagógica de Língua Espanhola do IFRN no ano de 2019.

Mais especificamente, os objetivos foram: 1) selecionar textos literários diversos para trabalhar nas aulas de espanhol do Ensino Médio de maneira a atrair e integrar os alunos e 2) desenvolver propostas didáticas com textos literários para aulas de língua espanhola em uma escola pública participante do projeto Residência Pedagógica do IFRN de maneira a integrar 
mais de uma habilidade linguística.

Estudos de Albaladejo (2007) e Cárcamo (2013) sobre a importância da literatura no ensino de língua espanhola, aliados aos nossos três anos de experiência como bolsistas no Programa Institucional de Bolsa de Iniciação à Docência (PIBID) e no programa Residência Pedagógica da Coordenação de Aperfeiçoamento de Pessoal de Nível Superior (CAPES) em escolas públicas de Educação Básica, têm constatado que o ensino de língua espanhola, nas escolas, segue ainda uma orientação predominantemente gramatical. Isso ocorre apesar do advento de novas metodologias de ensino de línguas estrangeiras, tais como o método comunicativo.

Embora já existam diversas pesquisas sobre o campo da competência leitora e o uso de textos literários, foi percebido que estudos voltados para o uso didático da literatura de forma prática, em especial, propostas que se dediquem à modalidade da Residência Pedagógica, que é historicamente recente, ainda não existem. Deste modo, se deu a relevância dessa pesquisa.

Redefinir o lugar do texto literário no que se refere ao ensino de línguas e aplicações didáticas tem sido uma das preocupações dos pesquisadores nessa área, tais como Santos (2007) e Cruz (2012). Em se tratando especificamente do ensino de Espanhol como Língua Estrangeira (E/LE), Mendoza (2007), Acquaroni (2007), Silva (2011, 2016), Silva e Aragão (2013), Aragão (2006) desenvolveram pesquisas relevantes sobre o tema em questão. Esses estudos têm propiciado a ampliação do debate a respeito do enfoque didático dado aos textos literários no ensino da língua espanhola, tanto nos cursos de formação docente como nos cursos de Educação Básica.

\section{Referencial Teórico}

Apresentamos aqui o referencial teórico e algumas discussões que subsidiaram nosso trabalho, a partir dos aportes de autores como Mendoza (2002, 2004, 2007), Acquaroni (2007), Albaladejo (2007), Aragão (2006), Silva (2011, 2016), entre outros estudiosos da área.

\subsection{A literatura e o ensino de espanhol como língua estrangeira}

Nesta seção, apresentaremos um breve resumo sobre a presença e o uso dos textos literários nas diferentes metodologias de ensino de língua estrangeira do século XX ao XXI conforme explicação de Muniz e Cavalcante (2009), Albaladejo (2007) e Gonçalves (2011). Em 
seguida trataremos especificamente da importância do uso da literatura no ensino da língua espanhola. Observaremos que o uso e a funcionalidade da literatura no contexto de ensinoaprendizagem de língua estrangeira passaram por diferentes momentos em função das transições metodológicas, conforme apresentamos a seguir.

Até por volta dos anos 1950 predominou no Brasil o padrão gramatical, também conhecido como método tradicional, no qual o foco de ensino era a tradução, memorização das regras gramaticais e imitação das amostras de língua consideradas "notáveis". Segundo Muniz e Cavalcante (2009), nessa metodologia, os textos literários eram um veículo perfeito para o ensino de uma língua estrangeira, exercendo apenas uma função instrumental de aprendizagem e fixação do modelo culto da língua a ser aprendida, descartando o desenvolvimento de atividades interpretativas e a compreensão dos textos.

Em meados da década de 1970 houve uma mudança na metodologia de ensino de línguas, a qual variou em função dos critérios linguísticos da época. Surgiram vários métodos, como por exemplo, o audiolingual e o audiovisual. Segundo Albaladejo (2007) e Gonçalves (2011), esses métodos objetivavam romper com a metodologia tradicional. Com isso, os textos literários foram suprimidos dos programas de ensino de línguas, e o estudo das estruturas linguísticas e do vocabulário passou para o primeiro plano. Além disso, esses novos métodos de ensino seguiam uma sequência por níveis em função da dificuldade que as estruturas e o vocabulário apresentavam para os alunos. Ademais, as obras literárias não se adequavam à referida nivelação.

Nos anos 1980, com o surgimento do modelo comunicativo, aconteceu uma verdadeira transformação, e todo o foco dos estudos recaiu sobre a aquisição da competência comunicativa. A partir do método comunicativo, a aprendizagem da língua estrangeira tinha por meta o desenvolvimento da capacidade de produzir enunciados na língua-alvo. Em resposta a essa nova demanda, a abordagem comunicativa priorizou a utilização de textos autênticos com o intuito de aproximar os alunos da realidade do uso da língua-alvo.

Essa valorização do uso de documentos autênticos como materiais textuais dava sinais de que beneficiaria diretamente a reincorporação da literatura no ensino de língua estrangeira. Entretanto, de acordo com Albaladejo (2007), o movimento comunicativo dos anos 1980 e seu carácter utilitarista desvia de seu foco tudo aquilo que não tivesse um propósito prático, e a 
literatura passou a ser vista como uma língua estática e muito distante das expressões comunicativas utilizadas no cotidiano.

Contudo, Acquaroni (2007, p.51) defende que mesmo parecendo um paradoxo, a literatura começa a surgir nos materiais didáticos de língua estrangeira, a partir do enfoque comunicativo, principalmente com o desenvolvimento de manuais didáticos baseados no foco por tarefas. Assim, a autora explica que o método comunicativo vai abrindo espaço à integração da literatura, embora de forma "desigual e assistemática".

Por fim, a partir dos anos 1990 o uso da literatura volta a ganhar espaço e, pouco a pouco, ela começa a ser incorporada nos materiais e métodos de ensino de línguas estrangeiras. Segundo Albaladejo (2007), a revalorização da literatura como instrumento didático para o ensino de línguas estrangeiras favoreceu ao aparecimento de várias obras dedicadas à exploração de textos literários no campo da metodologia da língua inglesa. Entretanto, o mesmo não ocorreu com o ensino da língua espanhola e são escassas as pesquisas relacionadas ao tema. Além disso, embora, nos livros didáticos, exista uma preocupação em inserir a literatura, normalmente, aparece apenas como um apêndice ao final das unidades, como um mero traço ornamental, cultural e quase exótico, sem qualquer relação com a proposta metodológica da unidade didática.

Nesse sentido, referindo-se, em particular, à poesia, não obstante podendo ser aplicado a todos os textos literários em geral, Acquaroni (2006 apud Albaladejo, 2007) discorre sobre as dificuldades enfrentadas pelo professor em incorporar os textos literários no desenvolvimento da aula.

Ya el hecho de situar el poema al final de la unidad está revelándonos, en muchos casos, las dificultades que dicho material plantea al profesor para incorporarlo realmente en el desarrollo de la clase: el poema queda así relegado a una posición de cierre marginal, de ejercicio voluntario que generalmente y por motivos de tiempo para el cumplimiento de la programación no se llega a realizar nunca en clase (ACQUARONI, 2006 apud ALBALADEJO, 2007, p. 4).

Portanto, podemos constatar que é premente encontrar estratégias para fazer com que a literatura se consolide uma parte mais significativa nos programas de ensino de línguas para estrangeiros.

2.2 Por que trabalhar a literatura na sala de aula de Espanhol como língua estrangeira (E/LE)? 
Continuamente, apresentaremos e discutiremos alguns aspectos principais que demonstram, em nossa opinião, a relevância e a necessidade de inserir os textos literários como recurso linguístico na aula de língua estrangeira, em especial, nas aulas de espanhol.

O ato de ler implica, segundo Freire (1989), na percepção crítica, na interpretação, na reescrita, na reelaboração do que lemos. Compreendemos a ação de ler a partir do nosso contexto pessoal e para ir além das linhas e entrelinhas, precisamos valorizar o ato de ler, que apenas começa na decodificação da palavra escrita. Ela se antecipa e perdura na inteligência do mundo.

De acordo com o educador, pedagogo e filósofo Paulo Freire, a leitura da palavra articula-se com a leitura de mundo, pois "A leitura da palavra é sempre precedida da leitura do mundo" (FREIRE, 1989, p.9). Isso significa dizer que a leitura do impresso veiculada em livros ou telas de eletrônicos, está intimamente relacionada com as experiências e as vivências dos leitores. Segundo Todorov, a literatura pode transformar o indivíduo, não é vazia, tem um papel a cumprir:

\begin{abstract}
A literatura pode muito. Ela pode nos estender a mão quando estamos profundamente deprimidos, nos tornar ainda mais próximos dos outros seres humanos que nos cercam, nos fazer compreender melhor o mundo e nos ajudar a viver. Não que ela seja, antes de tudo, uma técnica de cuidados para com a alma; porém, revelação do mundo, ela pode também em seu percurso, nos transformar a cada um de nós a partir de dentro. A literatura tem um papel vital a cumprir, mas para isso é preciso tomá-la no sentido amplo e intenso que prevaleceu na Europa até fins do século XIX e que hoje é marginalizado, quando triunfa uma concepção absurdamente reduzida do literário. (TODOROV, 2009, p.76).
\end{abstract}

Muito embora a literatura, atualmente, seja considerada um elemento constitutivo na formação do estudante, Cosson (2006) revela que, na prática, o texto literário, aos poucos, vem sendo substituído nos livros didáticos de língua portuguesa, principalmente nos do Ensino Fundamental, por textos jornalísticos, publicitários, entre outros. Entendemos a importância do estudo de diferentes gêneros textuais na escola e, por isso, defendemos que a literatura esteja presente, que a leitura do texto literário não esteja em segundo plano, como leitura complementar, ou o coloca à parte para o estabelecimento de atividades especiais de leitura.

O poder da literatura permite ao professor de Língua Espanhola pensar e repensar sobre o seu ensino. Sendo assim, entendemos que é relevante uma revisão sobre a concepção de ensino de língua espanhola, incluindo a leitura literária como parte fundamental para a formação humana. Segundo Cosson (2006), através da leitura literária, o leitor dialoga com outras visões da realidade que diferem das já conhecidas, como também se depara com algumas antes 
vivenciadas, uma vez que ela funciona como um processo de formação de sujeito leitor. Assim, a leitura de textos literários precisa manter um lugar especial nas escolas e na vida dos estudantes, pois ela possui a função de tornar o mundo compreensível, transformando palavras em sensações sinestésicas intensamente humanas.

Como observa Cosson (2014, p. 25), o letramento literário possibilita a apropriação da literatura como "construção literária de sentidos"; sendo assim, esse repertório é construído, transformado, negociado e preservado tanto individual como socialmente através desse letramento, ou seja, a leitura literária é uma atividade social necessária para a cidadania, é uma janela de acesso ao conhecimento, à cultura. Permite ao leitor vivenciar e compartilhar espaços, situações, conflitos, sonhos, emoções, dores e experiências de vida que ampliam seus referenciais, estimulando assim um novo olhar sobre um mesmo assunto.

A leitura no âmbito do letramento literário não é voltada apenas para a literatura, "mas sim uma experiência de dar sentido ao mundo por meio de palavras que falam de palavras, transcendendo os limites de tempo e espaço." (SOUZA; COSSON, 2011, p.103). Enquanto a literatura como instrumento não supõe o conjunto das obras e suas funções sociais inerentes a um dado objeto como o literário, mas o emprego desse conjunto em toda a sua complexidade.

Assim como Silva e Aragão (2013), entendemos que “a leitura pressupõe um diálogo entre o texto e o leitor, exigindo deste a ativação de todos os seus conhecimentos linguísticos, paralinguísticos, extralinguísticos, enciclopédicos e culturais para conseguir captar os significados da mensagem do texto" (SILVA, ARAGÃO, 2013, p. 161). No entanto, esse processo na língua estrangeira não é tão simples como aparenta, como nos mostra as autoras:

Em uma língua estrangeira, o leitor não conta com pistas sintáticas como o leitor nativo e, portanto, não pode fazer predições da mesma forma. Entretanto, o uso de um conjunto de estratégias durante a leitura em LE ajuda o leitor na sua interação com o texto, imprimindo-lhe significados com base nas suas vivências, expectativas e no seu conhecimento prévio. (SILVA, ARAGÃO, 2013, p. 161)

A partir dessa fundamentação, entendemos que o uso do texto literário nas aulas de língua estrangeira e, no caso em questão, de língua espanhola, contempla todos esses aspectos, dado que, entre tantos suportes de ensino, os textos literários ganham destaque, principalmente por seu valor autêntico, cultural, pragmático e sociolinguístico, e possibilitam a formação crítica e leitora do aprendiz. 


\subsection{A residência pedagógica no IFRN: uma parceria com a escola pública}

O programa Residência Pedagógica foi criado pelo Ministério da Educação atendendo às atribuições legais da CAPES conferidas pela Lei $N^{0} 8.405$, com o intuito de implementar projetos inovadores que estimulem articulação entre teoria e prática nos cursos de licenciatura em parceria com as redes públicas de educação básica e de acordo com as normas do Edital CAPES Nº6/2018, da Lei n 8.666 de 21 de junho de 1993, da Lei 9.784, de 29 de janeiro de 1999, da Lei 13.473 de 08 de agosto de 2017, do Decreto 8.752, de 09 de maio de 2016, Resolução CNE/CP n ${ }^{\circ}$ 02/2015, de $1^{\circ}$ de julho de 2015 da Portaria Capes n 38 de 28 de fevereiro de 2018 e demais dispositivos aplicáveis à matéria.

Fundamentada na imersão planejada e sistemática do aluno de licenciatura em ambiente escolar, a residência pedagógica visa à vivência e experimentação de situações concretas do cotidiano escolar e da sala de aula que depois servirão de objeto de reflexão sobre a articulação entre teoria e prática. Durante e após a imersão o residente é estimulado a refletir e avaliar sobre sua prática e relação com a profissionalização do docente escolar, para registro em relatório e contribuir para a avaliação de socialização de sua experiência como residente.

A nossa preparação para a residência contou com atividades pré-definidas: reunião dos preceptores com os residentes para análise dos diagnósticos realizados nas escolas-campo; elaboração do planejamento das ações de regência do residente para as escolas-campo; definição das ações didático-pedagógicas a serem implementadas nas escolas, articulando as ações do plano de trabalho do subprojeto referente à área de atuação do aluno residente; elaboração de planos de intervenção baseadas na análise do contexto escolar, considerando as condições objetivas e subjetivas do processo de ensino-aprendizagem, os conteúdos escolares e as metodologias inovadoras articuladas aos programas institucionais do MEC desenvolvidos nas escolas e a BNCC e discussão e análise dos projetos de intervenção dos residentes com o docente preceptor e a comunidade escolar.

Além disso, tivemos ações complementares de acompanhamento da preparação dos residentes, tais como reuniões com docentes orientadores, preceptores e residentes para avaliação dos subprojetos, bem como dos planos de atividades e intervenção desenvolvidos nas escolas parceiras; acompanhamento realizado pelos docentes orientadores às escolas parceiras, com vistas ao acompanhamento dos trabalhos desenvolvidos pelos preceptores e os residentes; acompanhamento do trabalho didático-pedagógico através de ficha de frequência, de descrição 
e análise das atividades desenvolvidas, roteiros para sistematização dos projetos de intervenção, de organização das sequências didáticas dentre outros, para acompanhamento e avaliação dos subprojetos e dos projetos de intervenção de cada residente e elaboração de portfólios, diários de bordo, relatórios, artigos científicos com análise e avaliação da experiência desenvolvida pelo IFRN, docentes orientadores, preceptores e residentes.

No IFRN-Campus Natal Central, os bolsistas que fizeram parte deste programa, na área de língua espanhola, atuaram em uma escola estadual no bairro de Mãe Luiza na cidade de Natal, no Rio Grande do Norte. Foram realizadas oficinas de língua espanhola com temas variados com o objetivo de realizar um maior contato dos alunos com a língua espanhola, em especial com a leitura literária com atividades que serão propostas. $\mathrm{O}$ trabalho foi realizado com alunos do ensino médio, visando desenvolver um conhecimento literário em língua espanhola com as escolhas dos textos selecionados.

\section{Metodologia}

Esta pesquisa é de natureza qualitativa, na medida em que foram propostas atividades aplicadas, dentro do contexto da Residência Pedagógica 2018. E pode ser classificada como bibliográfica, pois é desenvolvida com base em material já elaborado e, quanto aos procedimentos técnicos, a pesquisa agregou traços exploratórios, pois tratou de uma abordagem bibliográfica.

O estudo se voltou para propostas de intervenção em um caso e um contexto específico, tendo em vista contribuir com o crescimento dos sujeitos (alunos do ensino médio de uma escola pública em que atuamos como bolsistas do programa residência pedagógica). Por conta disso optamos por utilizar o método hipotético-dedutivo, uma vez que, a indução é compreendida como parte de uma coerência metodológica porque é justificada dedutivamente. Sua justificação indutiva exigiria o trabalho de sua verificação factual. Isso significaria cair numa petição de princípio, ou seja, apoiar-se numa demonstração sobre a tese que se pretende demonstrar. No método hipotético-dedutivo, de acordo com Kaplan (1972):

(...) o cientista, através de uma combinação de observação cuidadosa, hábeis antecipações e intuição científica, alcança um conjunto de postulados que governam os fenômenos pelos quais está interessado, daí deduz ele as consequências por meio de experimentação e, dessa maneira, refuta os postulados, substituindo-os, quando necessário, por outros, e assim prossegue. (KAPLAN, 1972, p. 12) 
Nessa perspectiva metodológica do método hipotético-dedutivo, a relação entre pesquisador e objeto do conhecimento acontece numa conjunção entre a razão e a experimentação de hipóteses submetidas à prova.

Os sujeitos da nossa pesquisa foram 12 (doze) alunos do Ensino Médio de uma escola da Rede Estadual de Educação do Rio Grande do Norte, porém, durante as oficinas a quantidade de alunos variava de oito a doze alunos, isso ocorria por ser no contraturno das aulas e os alunos precisarem sair para resolver problemas pessoais.

A instituição campo de pesquisa foi uma escola da rede estadual de ensino médio da cidade do Natal e a escolha se deu por ser a escola campo da Residência Pedagógica e ser nosso campo de atuação. A escola está situada no bairro de Mãe Luiza, no município de Natal, e mantém atividades no turno vespertino com a referida modalidade que ocorriam no período das $13 \mathrm{~h} 30 \mathrm{~min}$ às $15 \mathrm{~h}$.

\subsection{Procedimentos metodológicos para o planejamento das aulas}

Pensar o ensino da literatura e suas modalidades práticas infere que se defina a finalidade desse ensino. É a formação de um sujeito leitor livre, responsável e crítico, capaz de construir o sentido de modo autônomo e de argumentar sua recepção. Instituir o aluno sujeito leitor tratase de, ao mesmo tempo, partir da recepção do aluno, de convidá-lo à aventura interpretativa com seus riscos, reforçando suas competências pela aquisição de saberes e de técnicas.

As pesquisas atuais em didática da literatura mostram que é a atenção dada ao aluno, enquanto sujeito, a sua fala e a seu pensamento construído na e pela escrita que favorece seu investimento na leitura. A importância do clima estabelecido no interior da comunidade interpretativa (a classe, o professor) é enfatizada: um contexto em que reinam a confiança, o respeito e a escuta mútuos é propicio ao encontro com textos literários.

Assim, as propostas aqui idealizadas e executadas foram adaptadas com base nos estudos formulados por Silva (2011, 2016) e outros estudiosos como Solé (1998), Mendoza (2004) e Acquaroni (2007), que propõem que a aula de leitura seja dividida em três momentos: préleitura, momento para despertar o interesse, o levantamento dos conhecimentos prévios; a leitura, onde o aluno deverá compreender o texto, decodificando o código escrito e a pós-leitura que é o momento destinado para a interpretação. 
Por questão de tempo, nem todas as atividades foram aplicadas. Neste artigo, trataremos somente das atividades que foram aplicadas. O tempo disponível para cada proposta foi de $2 \mathrm{~h} / \mathrm{a}$ (quarenta e cinco minutos cada aula). No quadro 1 a seguir explanamos a data de aplicação das propostas, o gênero do texto trabalhado e o título do texto juntamente com seu autor.

Quadro 1 - Especificações das propostas de aula.

\begin{tabular}{|l|l|l|}
\hline Data da Aplicação & Gênero & Texto literário trabalhado \\
\hline 09 abr. 2019 & Conto & Teoría del cangrejo - Júlio Cortazár \\
\hline 11 abr. 2019 & Romance & La noche de los feos - Mario Benedetti \\
\hline 16 abr. 2019 & Poema & Hombre de color - Léopold Sédar Senghor \\
\hline
\end{tabular}

Fonte: Lima (2019, p. 25).

Nas Orientações Curriculares para o Ensino Médio-OCEM (BRASIL, 2006), há menção para a leitura literária somente na língua materna: "trata-se, prioritariamente, de formar o leitor literário, melhor ainda, de 'letrar' literariamente o aluno, fazendo-o apropriar-se daquilo a que tem direito.” (BRASIL, 2006, p. 54), entretanto, segundo Silva e Aragão (2013), no capítulo destinado ao ensino da língua estrangeira, o referido documento não apresenta nenhuma orientação.

Com isso, apresentamos, a seguir, algumas sugestões para trabalhar a leitura literária em língua espanhola nas oficinas da Residência Pedagógica baseados nos princípios norteadores elencados por Silva (2016), que são essenciais para o trabalho com a leitura literária em espanhol no ensino médio, conforme parafraseamos abaixo:

$1^{\mathrm{o}}$ - os textos literários devem ser autênticos, acessíveis, motivadores e que possam integrar as diversas habilidades.

$2^{\circ}$ - os textos escolhidos devam estar de comum acordo com o gosto tanto dos educandos como do docente, para que um não sobressaia o do outro;

$3^{\circ}$ - as atividades devem considerar o filtro afetivo, considerando as motivações dos alunos e buscando elevar a autoestima;

$4^{\mathrm{o}}$ - necessidade de planejar atividades com pré-leitura, leitura e pós leitura de acordo com a necessidade da turma;

$5^{\circ}$ - a autora orienta a não enxergar o TL como pretexto para aula de gramática, de 
resumos ou de qualquer atividade que desvinculem o texto literário da sua objetividade que é a formação para o enriquecimento da competência comunicativa;

$6^{\circ}$ - a autora destaca que o TL não é o único capaz de desenvolver habilidades linguísticas, mas que seu trabalho sistematizado pode render uma melhora no desenvolvimento das habilidades de compreensão leitora e da competência literária;

$7^{0}$ - a referida autora nos direciona para que desconstruamos a visão de que textos literários maiores não devem ser trabalhados e aponta para o uso de fragmentos de obras bem selecionados pelo docente, que deverá conter unidade de sentido e que são capazes de despertar no leitor o interesse por obras maiores;

$8^{\circ}$ - o texto literário é uma fonte de situação comunicativa em que se pode apropriar de formas linguísticas e socioculturais da língua estudada;

$9^{\circ}$ - a leitura e as atividades em grupo devem ser estímulos para o conhecimento dos alunos, já que as trocas permitem o desenvolvimento;

$10^{\circ}$ - o foco da aula de leitura literária deve ser a compreensão leitora e que é possível que o docente elabore atividades para o desenvolvimento de algumas das habilidades linguísticas.

Partindo dessas considerações para o trabalho sistematizado com textos literários, apresentamos, na figura 1, as diretrizes seguidas no presente trabalho, a partir das orientações de Silva (2016). Essas orientações estão também amparadas pelas concepções de teóricas de Mendoza (2002, 2004, 2007), Acquaroni (2007), Albaladejo (2007), Aragão (2006) e outros estudiosas da área. 
Figura 1 - Diretrizes para trabalhar leitura literária em espanhol no ensino médio

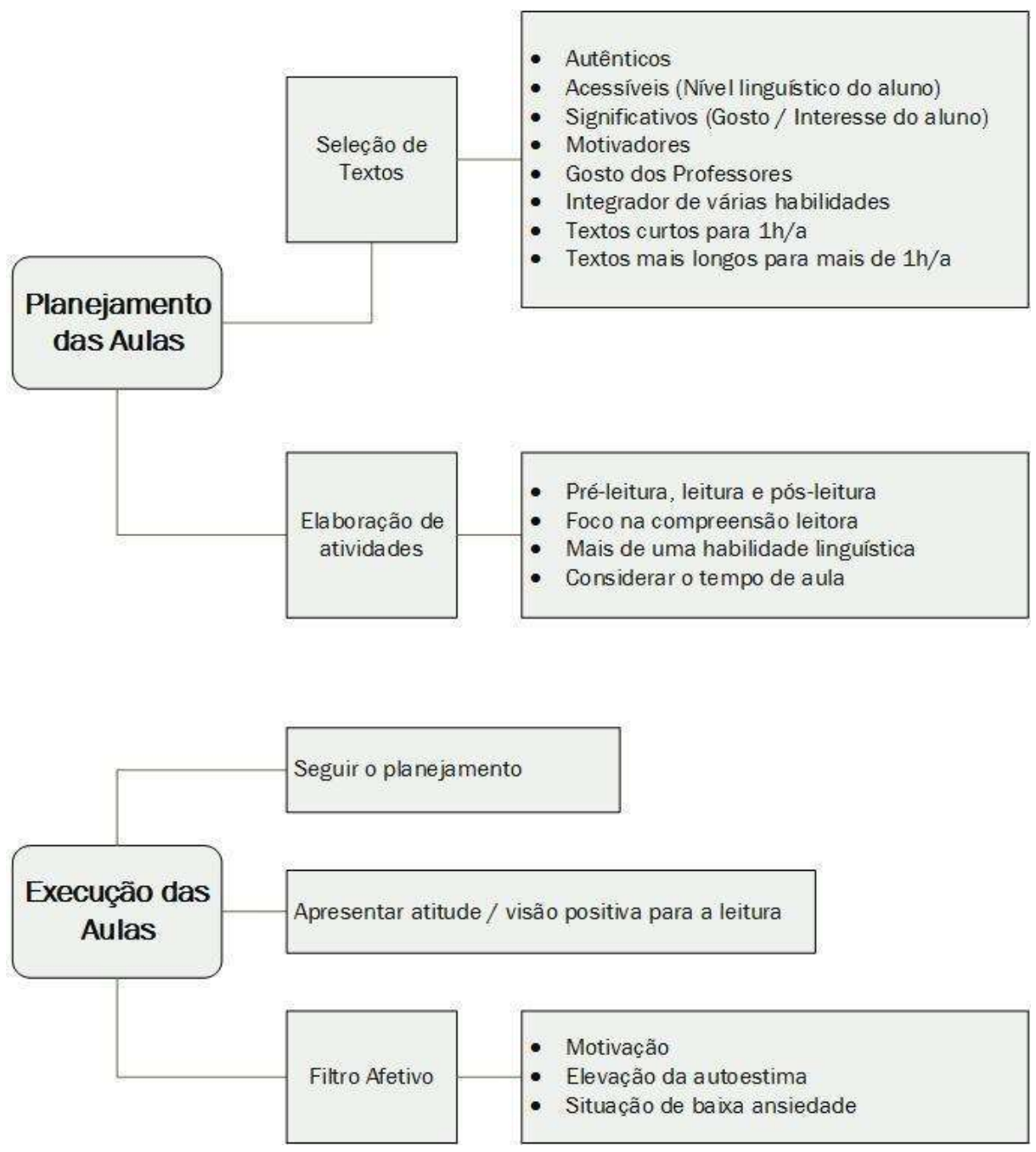

Fonte: Silva (2016, p. 27).

\section{Propostas didáticas de leitura literária em língua espanhola no ensino médio}

Durante o período de agosto de 2018 a agosto de 2019 em que atuamos na residência pedagógica, aplicamos algumas propostas, conforme descrevemos a seguir. Cada proposta foi aplicada com duração de 2 h/a (45 minutos cada aula). Ressaltamos que algumas interações durante a leitura eram feitas em língua materna, porém sempre estimulávamos e conduzíamos as falas para que o aluno também tentasse se expressar na língua espanhola.

Compreendemos que não há modelos fixos para serem seguidos no que tange à leitura literária, uma vez que um grupo de alunos não é simular ao outro. Optamos por realizar atividades que abordem mais de uma temática e que possa ser de géneros literários distintos, 
visto que temos o intuito de apresentar aos alunos leituras que o levem a alguma reflexão e que os incentivem a se tornarem leitores mais vorazes.

Inicialmente, escolhemos o miniconto chamado "Teoría del Cangrejo" do escritor argentino Júlio Cortázar. Na primeira fase, sondamos se os alunos conhecem o escritor do miniconto, se eles sabem a estrutura desse gênero e se eles possuem o hábito de ler textos assim. Posteriormente, entregamos o miniconto para que os alunos o lessem e, na fase final, indagamos a respeito do título e se eles se identificam com os fatos que ocorrem no texto.

A segunda proposta consiste em trabalhar o conto "La noche de los feos", de Mario Bendetti. A princípio, relembramos com os alunos quais são as características desse gênero. Em seguida, colocaremos no quadro o seguinte questionamento: para vocês o que é o feio? Conversamos a respeito das considerações feitas pelos alunos e comentamos sobre o texto de Benedetti. Após esse momento, destinamos um tempo para que os alunos lessem o texto e depois solicitamos que eles produzam uma frase com o tema de: "El feo es ".

Na terceira atividade, apresentamos para os alunos o poema de Léopold Sédar Senghor: Hombre de color. No primeiro momento, perguntamos para eles se acreditam que no Brasil ainda há muito racismo, se essa questão está disfarçada ou em segundo plano na nossa sociedade. Em seguida, mostramos o poema aos alunos, pedimos para que eles o leiam silenciosamente. Após a leitura, solicitamos-lhes que escrevam o que é preconceito para eles e como ele interferem em suas vidas.

\subsection{Primeira aula: conto}

$\mathrm{Na}$ aula 1, trabalhamos um miniconto do autor Júlio Cortázar, chamado "Teoría del cangrejo".

Quadro 2: Conto "Teoría del cangrejo"

\section{Teoría del cangrejo}

Habían levantado la casa en el límite de la selva, orientada al sur para evitar que la humedad de los vientos de marzo se sumara al calor que apenas mitigaba la sombra de los árboles.

Cuando Winnie llegaba

Dejó el párrafo en suspenso, apartó la máquina de escribir y encendió la pipa. Winnie. El problema, como siempre, era Winnie. Apenas se ocupaba de ella la fluidez se coagulaba en una especie de

Suspirando, borró en una especie de, porque detestaba las facilidades del idioma, y pensó que ya no podría seguir trabajando hasta después de cenar; pronto llegarían los niños 
de la escuela y habría que ocuparse de los baños, de prepararles la comida y ayudarlos en sus

¿Por qué en mitad de una enumeración tan sencilla había como un agujero, una imposibilidad de seguir? Le resultaba incomprensible, puesto que había escrito pasajes mucho más arduos que se armaban sin ningún esfuerzo, como si de alguna manera estuvieran ya preparados para incidir en el lenguaje. Por supuesto, en esos casos lo mejor era

Tirando el lápiz, se dijo que todo se volvía demasiado abstracto; los por supuesto y los en esos casos, la vieja tendencia a huir de situaciones definidas. Tenía la impresión de alejarse cada vez más de las fuentes, de organizar puzzles de palabras que a su vez

Cerró bruscamente el cuaderno y salió a la veranda.

Imposible dejar esa palabra, veranda.

$$
\text { Fonte: }<\text { https://ciudadseva.com/texto/teoria-del-cangrejo/>. Acesso em } 27 \text { nov. } 2019
$$

\section{Pré leitura (30min):}

Escrevemos o título do conto no quadro e pedimos que os alunos fossem construindo significados para o que estava escrito de forma oral. Os alunos lançaram ideias a respeito do título, explanando o que para eles seria a "teoria do caranguejo". Falas como "é sobre quem anda pra trás" foram ditas. Estes significados foram construídos a partir dos conhecimentos que o aluno já possuía. Neste viés, Mendoza (2007) nos aponta que esta interpretação é "resultado de uma adequada e coerente (re) construção de significados que se estabelece a partir de inferências consolidadas após seguir atividades do processo de recepção.” (MENDOZA, 2007, p.93).

Após algumas intervenções, direcionamos os alunos a uma reflexão, abordando a temática da procrastinação, isto é, postergar afazeres, e não conseguir concluir algo que se começou, isto tudo com intuito de construir uma equivalência para o título do conto "teoría del cangrejo". Seguimos perguntando se alguém vivenciava isso e se sentiam-se mal por esse motivo, fazendo com que eles observassem a própria realidade.

\section{Leitura (30min):}

Após o momento de discussão, realizamos a distribuição do texto literário para que os alunos fizessem a leitura individual, e como já era de costume, os alunos logo reclamaram que não entenderiam nada do texto pois estava em espanhol. Fizemos algumas intervenções, sempre apontando para motivação dos alunos que é algo de extrema importância, visto que muitos possuem iniciativa própria para realizar a leitura e outros precisam que o professor insista e, em alguns casos, chame a atenção para que eles consigam foco e concentração. 
Após o momento de leitura individual, realizamos a leitura mediada, que, de acordo com Freitas (2012), “apoia o leitor iniciante auxiliando-o a mobilizar conhecimentos anteriores para desenvolver as habilidades específicas para aquela tarefa" (FREITAS, 2012, p.68) e esclarece dúvidas que surgiram durante a leitura do conto além de promover a reflexão acerca do tema tratado no debate promovido anterior a leitura. Neste momento, os alunos começaram a expor pensamentos e ideias, construindo suas próprias considerações acerca do texto. Sempre que falavam em português, respondíamos em espanhol, estimulando que a interação ocorresse na língua estrangeira. Muitos falaram da estranheza que sentiram ao ler o texto, pois havia estruturas textuais inacabadas, como frases sem ponto final e parágrafos sem continuação.

\section{Pós leitura (30min):}

Durante a pós leitura, organizamos as cadeiras da sala em formato de círculo para que pudéssemos refletir a respeito do texto de uma forma mais acolhedora e demos início ao nosso debate. Questionamos aos alunos se eles tinham feito uma associação com o título do conto, a discussão que tivemos anterior a leitura e ao texto lido. Alguns alunos conseguiram correlacionar esses três aspectos da aula, explicando com suas palavras que se tratava de quem não conseguia terminar o que começava deixando sempre para depois, com a metáfora do modo como o caranguejo andava (de lado) e nunca para a frente e sobre a estrutura do texto por não ter pontuação encerrando períodos, ou conclusão de ideias em algumas partes. Apenas dois de doze alunos presentes na aula chegaram a essa conclusão, os outros dez alunos ficaram confusos com o texto escolhido e não fizeram esta correspondência que os outros construíram.

\subsection{Segunda aula: romance}

$\mathrm{Na}$ aula 2, trabalhamos o gênero conto intitulado por "La noche de los feos" do autor Mario Benedetti.

Quadro 3: Conto "la noche de los feos"

\section{La noche de los feos \\ 1}

Ambos somos feos. Ni siquiera vulgarmente feos. Ella tiene un pómulo hundido. Desde los ocho años, cuando le hicieron la operación. Mi asquerosa marca junto a la boca viene de una quemadura feroz, ocurrida a comienzos de mi adolescencia. 
Tampoco puede decirse que tengamos ojos tiernos, esa suerte de faros de justificación por los que a veces los horribles consiguen arrimarse a la belleza. No, de ningún modo. Tanto los de ella como los míos son ojos de resentimiento, que sólo reflejan la poca o ninguna resignación con que enfrentamos nuestro infortunio. Quizá eso nos haya unido. Tal vez unido no sea la palabra más apropiada. Me refiero al odio implacable que cada uno de nosotros siente por su propio rostro.

Nos conocimos a la entrada del cine, haciendo cola para ver en la pantalla a dos hermosos cualesquiera. Allí fue donde por primera vez nos examinamos sin simpatía pero con oscura solidaridad; allí fue donde registramos, ya desde la primera ojeada, nuestras respectivas soledades. En la cola todos estaban de a dos, pero además eran auténticas parejas: esposos, novios, amantes, abuelitos, vaya uno a saber. Todos -de la mano o del brazo- tenían a alguien. Sólo ella y yo teníamos las manos sueltas y crispadas.

Nos miramos las respectivas fealdades con detenimiento, con insolencia, sin curiosidad. Recorrí la hendidura de su pómulo con la garantía de desparpajo que me otorgaba mi mejilla encogida. Ella no se sonrojó. Me gustó que fuera dura, que devolviera mi inspección con una ojeada minuciosa a la zona lisa, brillante, sin barba, de mi vieja quemadura.

Por fin entramos. Nos sentamos en filas distintas, pero contiguas. Ella no podía mirarme, pero yo, aun en la penumbra, podía distinguir su nuca de pelos rubios, su oreja fresca bien formada. Era la oreja de su lado normal.

Durante una hora y cuarenta minutos admiramos las respectivas bellezas del rudo héroe y la suave heroína. Por lo menos yo he sido siempre capaz de admirar lo lindo. Mi animadversión la reservo para mi rostro y a veces para Dios. También para el rostro de otros feos, de otros espantajos. Quizá debería sentir piedad, pero no puedo. La verdad es que son algo así como espejos. A veces me pregunto qué suerte habría corrido el mito si Narciso hubiera tenido un pómulo hundido, o el ácido le hubiera quemado la mejilla, o le faltara media nariz, o tuviera una costura en la frente.

La esperé a la salida. Caminé unos metros junto a ella, y luego le hablé. Cuando se detuvo y me miró, tuve la impresión de que vacilaba. La invité a que charláramos un rato en un café o una confitería. De pronto aceptó.

La confitería estaba llena, pero en ese momento se desocupó una mesa. A medida que pasábamos entre la gente, quedaban a nuestras espaldas las señas, los gestos de asombro. Mis antenas están particularmente adiestradas para captar esa curiosidad enfermiza, ese inconsciente sadismo de los que tienen un rostro corriente, milagrosamente simétrico. Pero esta vez ni siquiera era necesaria mi adiestrada intuición, ya que mis oídos alcanzaban para registrar murmullos, tosecitas, falsas carrasperas. Un rostro horrible y aislado tiene evidentemente su interés; pero dos fealdades juntas constituyen en sí mismas un espectáculo mayor, poco menos que coordinado; algo que se debe mirar en compañía, junto a uno (o una) de esos bien parecidos con quienes merece compartirse el mundo.

Nos sentamos, pedimos dos helados, y ella tuvo coraje (eso también me gustó) para sacar del bolso su espejito y arreglarse el pelo. Su lindo pelo.

“QQué está pensando?”, pregunté.

Ella guardó el espejo y sonrió. El pozo de la mejilla cambió de forma.

"Un lugar común", dijo. "Tal para cual".

Hablamos largamente. A la hora y media hubo que pedir dos cafés para justificar la prolongada permanencia. De pronto me di cuenta de que tanto ella como yo estábamos hablando con una franqueza tan hiriente que amenazaba traspasar la sinceridad y convertirse en un casi equivalente de la hipocresía. Decidí tirarme a fondo. 


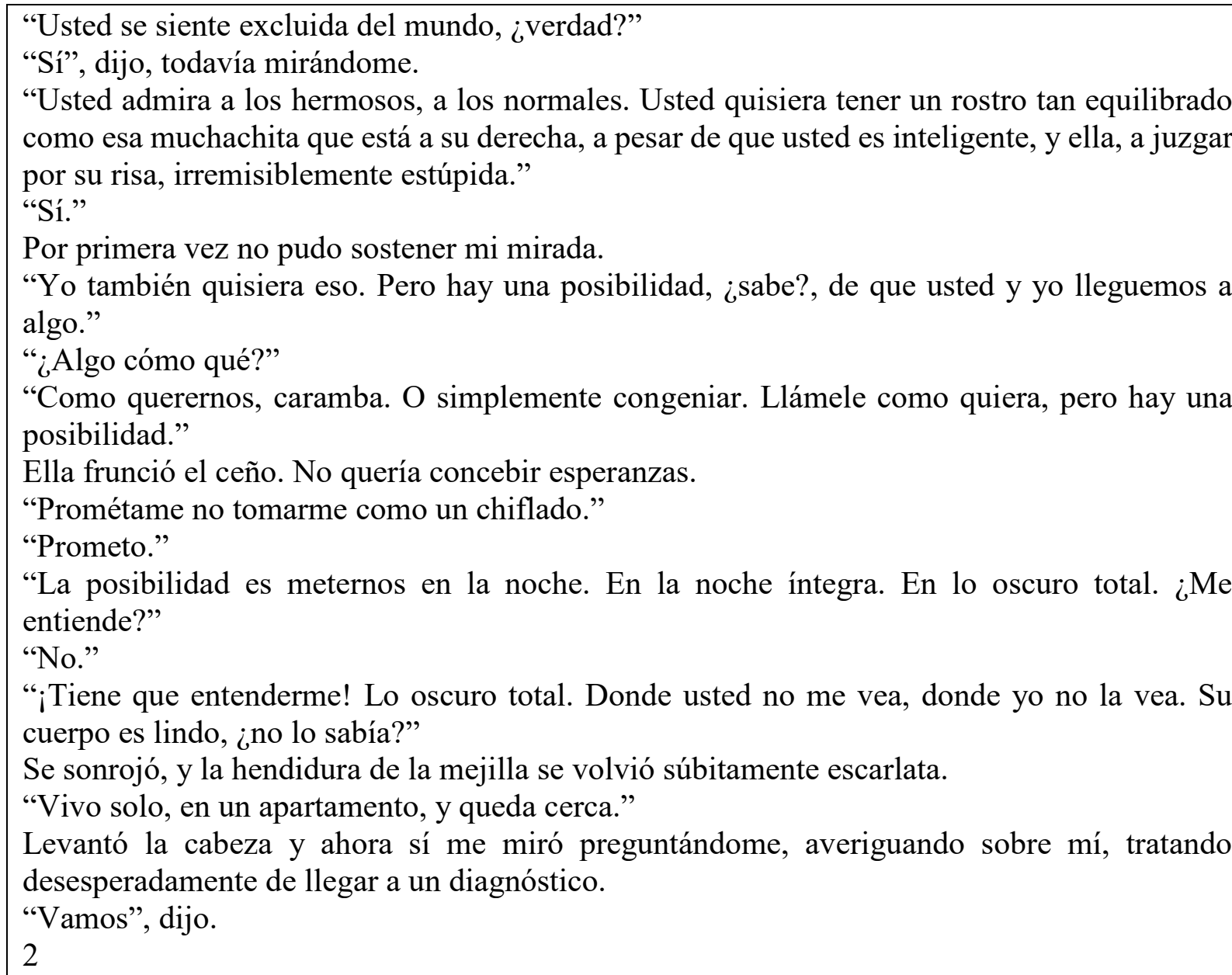

No sólo apagué la luz sino que además corrí la doble cortina. A mi lado ella respiraba. Y no era una respiración afanosa. No quiso que la ayudara a desvestirse.

Yo no veía nada, nada. Pero igual pude darme cuenta de que ahora estaba inmóvil, a la espera. Estiré cautelosamente una mano, hasta hallar su pecho. Mi tacto me transmitió una versión estimulante, poderosa. Así vi su vientre, su sexo. Sus manos también me vieron.

En ese instante comprendí que debía arrancarme (y arrancarla) de aquella mentira que yo mismo había fabricado. O intentado fabricar. Fue como un relámpago. No éramos eso. No éramos eso.

Tuve que recurrir a todas mis reservas de coraje, pero lo hice. Mi mano ascendió lentamente hasta su rostro, encontró el surco de horror, y empezó una lenta, convincente y convencida caricia. En realidad mis dedos (al principio un poco temblorosos, luego progresivamente serenos) pasaron muchas veces sobre sus lágrimas.

Entonces, cuando yo menos lo esperaba, su mano también llegó a mi cara, y pasó y repasó el costurón y el pellejo liso, esa isla sin barba de mi marca siniestra.

Lloramos hasta el alba. Desgraciados, felices. Luego me levanté y descorrí la cortina doble.

Fonte: < https:/ciudadseva.com/texto/la-noche-de-los-feos/ >. Acesso em 27 nov. 2019

A temática escolhida estava relacionada aos padrões de beleza impostos pela sociedade, em que aquele que não se encaixa nesse arquétipo posto pela sociedade atual está fadado à exclusão das maiorias. Uma das grandes vantagens que o professor tem, ao decidir levar o TL 
para sua sala de aula, é que poderá encontrar textos literários para temáticas diversas. Cosson (2014) afirma que, "por meio da literatura, temos acesso a uma grande diversidade de textos, pois é próprio do discurso literário a multiplicidade das formas e a pluralidade dos temas" (COSSON, 2014, p.49).

\section{Pré leitura (30min):}

Durante a pré-leitura, escrevemos, no quadro, o seguinte questionamento "Na sua opinião, o que significa a palavra feio?". Em seguida, mediamos um breve debate acerca do tema, em que os alunos responderam que "o feio" era algo diferente e que não se encaixava em um padrão. Os alunos estavam muito motivados durante a reflexão e relataram situações pessoais de exclusão já vividas, pelo fato de outras pessoas os acharem fora de determinado padrão. Logo após este momento, tivemos que reduzir o tempo das discussões para conseguirmos executar o plano de aula por inteiro

\section{Leitura (30min):}

Posteriormente, entregamos o conto e pedimos para que eles fizessem uma leitura individual e silenciosa. Alguns alunos reclamaram do tamanho do texto e disseram que não conseguiriam entender, outros alunos demonstraram interesse no que estava sendo lido e enfatizaram compreensão de palavras já conhecidas por eles.

Após a leitura individual, fizemos a leitura para todos os alunos e, a medida em que lemos, realizamos explicações sobre palavras, estruturas e outras questões linguísticas. Logo, relembramos a reflexão feita antes da leitura do texto, sempre conduzindo a discussão em língua espanhola, levando os alunos a se esforçaram para construir o máximo de estruturas em língua espanhola. Isso era uma característica marcante dessa turma. Inicialmente tinham resistência para falar em espanhol, mas quando eram instigados a falar livremente em LE, logo se animavam e interagiam.

\section{Pós leitura (30min):}

Durante a pós-leitura, escrevemos, no quadro, a frase "El feo es..." e explicamos aos alunos que, em uma folha, deveriam escrever uma frase concluindo o conceito do enunciado e sistematizando as ideias que tinham sido expostas durante a aula. Os alunos ficaram apavorados 
com o fato de escrever e disseram que não sabiam. Alguns alunos, de imediato, iniciaram a frase e os que estavam com mais dificuldades, solicitavam a nossa ajuda. Por fim, pedimos que eles lessem o que tinham produzido e compartilhassem com a turma. Uns, de forma mais ágil, logo leram. Outros, mais timidamente, pediram nossa ajuda e, em seguida, também realizaram a leitura. No final, todos escreveram e leram o que tinham escrito.

\subsection{Terceira aula: poema}

Na aula 3, utilizamos um poema do autor Léopold Sédar Senghor, chamado "Hombre de color".

Quadro 4: Poema "hombre de color"

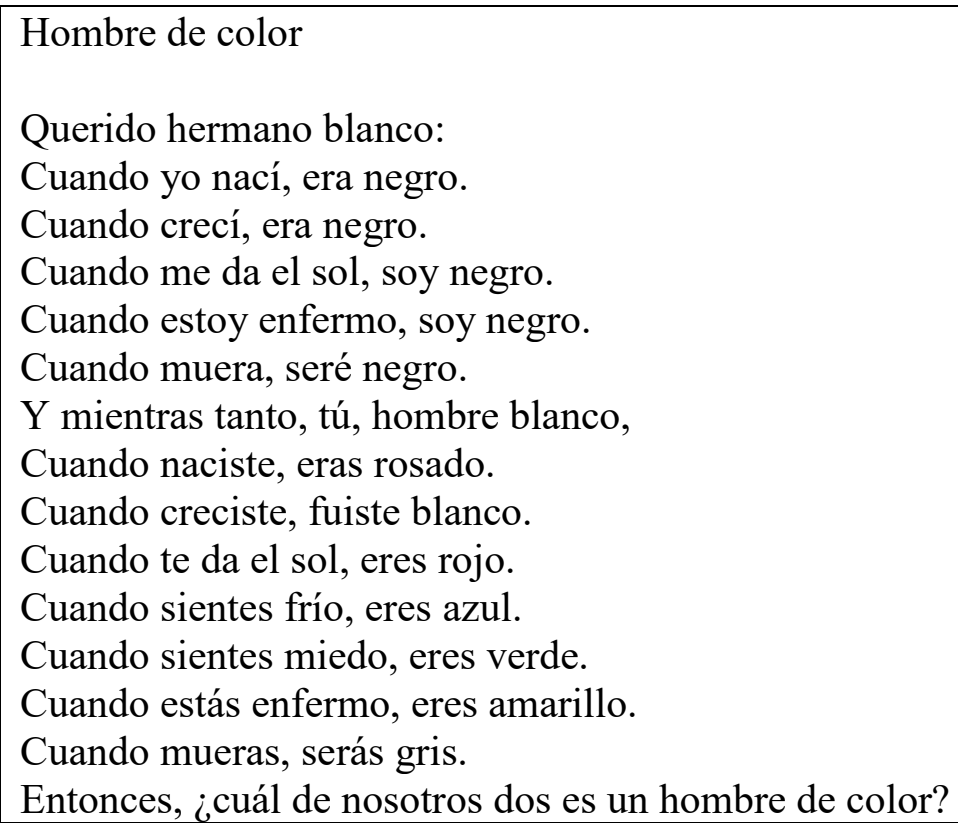

\section{Pré leitura (30min):}

Demos início à aula mostrando dados a respeito do racismo no Brasil. Após algumas intervenções dos alunos, seguimos para a pré-leitura, questionando-os sobre o racismo no nosso país e o que eles achavam. As respostas e reflexões serviram para construir uma relação com o texto a ser entregue no segundo momento. Com o objetivo de auxiliar o aluno no direcionamento dos seus conhecimentos para a interpretação e compreensão do texto, seguimos perguntando se alguém vivenciava isso, levando-os a uma reflexão sobre a própria realidade. 


\section{Leitura (30min):}

Após o momento de discussão, distribuímos o texto literário para que os alunos fizessem a leitura individual. Em seguida, realizamos a leitura mediada, com o intuito de apoiar os alunos que apresentaram dúvidas. Esclarecemos as que surgiram durante a leitura do poema, objetivando promover a reflexão acerca do tema tratado no debate promovido anterior à leitura. Neste momento, os alunos começaram a expor pensamentos e ideias, continuaram construindo suas percepções acerca do texto.

\section{Pós leitura (30min):}

Em seguida, pedimos para os alunos produzirem um pequeno texto sobre o racismo e a interferência dele nas suas vidas. Posteriormente, eles compartilharam oralmente o que tinham feito. Foram opiniões diversas, desde "Eu acho que o Brasil melhorou muito no aspecto racismo" à "O Brasil permanece o mesmo país racista de sempre, só que agora muita coisa é escondida." Observamos o interesse, a participação, o desenvolvimento e o envolvimento dos alunos de forma mais ativa quando trabalhamos este poema com esta temática. Todos tinham algo para relatar, opinar ou contestar e sempre tentando falar em espanhol.

\section{Considerações Finais}

Ao fim desta pesquisa, apresentamos nossas respostas aos objetivos propostos. Para responder ao primeiro objetivo específico: "selecionar textos literários diversos para trabalhar nas aulas de espanhol do Ensino Médio de maneira a atrair e integrar os alunos", afirmamos que, em nossas leituras pudemos nos aprofundar em estudos que explanam sobre os benefícios que a TL traz para os estudantes e que, quando bem selecionados para as aulas de E/LE, contribui para o desenvolvimento da competência leitora e literária, bem como ajuda na formação de um leitor crítico, como também favorece a formação de um pensamento a respeito de questões éticas, políticas, sociais e ideológicas.

Em resposta ao nosso segundo objetivo específico: “desenvolver propostas didáticas com textos literários para aulas de língua espanhola em uma escola pública participante do projeto Residência Pedagógica do IFRN de maneira a integrar mais de uma habilidade linguística", desenvolvemos propostas de aulas com o uso dos gêneros literários integradoras de mais de uma habilidade e estruturadas com pré-leitura, leitura e pós- leitura. 
Considerando as dificuldades enfrentadas pelos professores, atentamos agora para o horário destinado a disciplina de língua espanhola nas escolas, trabalhar a leitura é um desafio na prática docente e quando falamos em literatura o desafio se configura ainda maior, principalmente no âmbito da língua estrangeira. Com isso, as propostas aqui explanadas, podem ser recortadas e divididas em duas aulas, considerando que o tempo destinado a cada oficina era de $2 \mathrm{~h} / \mathrm{a}$ (45min cada aula).

A leitura literária se apresenta como um instrumento didático de grandes possibilidades e contribui para o crescimento do desenvolvimento da competência leitora e literária, assim como também auxilia na criação de um olhar mais crítico ao proporcionar ao aluno uma nova perspectiva de mundo através da literatura. É imprescindível, pois, que o convívio com os livros extrapole o desenvolvimento sistemático da sua escolarização e que a literatura passe a se difundir com mais intensidade nas escolas.

Nenhum professor deverá se intimidar de colocar em prática seus projetos literários, compartilhar suas leituras com os alunos, fazendo comentários ou interpretações que aguce nos estudantes a sensibilidade, o senso crítico, a capacidade argumentativa e a curiosidade. A escola é uma das responsáveis pela formação ética, crítica e reflexiva do indivíduo. Em virtude disso, é relevante que se incluam, nesse espaço, momentos que possibilitem ao aluno, aprender a linguagem através da multiplicidade de textos e, consequentemente, das particularidades dos gêneros, criando assim, situações propícias ao desenvolvimento da capacidade leitora.

\section{Referências}

ACQUARONI, Rosana. Las palabras que no se lleva el viento: literatura y enseñanza de español como LE/L2. Madrid: Santillana, 2007. 264p.

ALBALADEJO, María Dolores Gracía. Cómo llevar la literatura al aula de ELE: de la teoría a la práctica. Marco ELE: Revista de Didáctica Español Lengua Extranjera, n. 5, 2007.

Disponível

em: http://www.marcoele.com/num/5/02e3c0099fc0b38904/albaladejo.pdf. Acesso em: 21 out. 2019.

BRASIL. Lei $\mathbf{n}^{0}$ 11.161, de 5 de agosto de 2005. Dispõe sobre o ensino da língua espanhola. Diário Oficial da União, Brasília, DF, 8 ago. 2005, p. 1. Disponível em: http://www.planalto.gov.br/ccivil 03/ Ato20042006/2005/Lei/L11161.htm. Acesso em: 10 out. 2019

BRASIL. Ministério da Educação. Secretaria de Educação Básica. Orientações Curriculares para o Ensino Médio: Linguagens, códigos e suas tecnologias. Brasília, 2006. 
Disponível

em:

"http://portal.mec.gov.br/seb/arquivos/pdf/book_volume_01_internet.pdf". Acesso em 10 out. 2019.

BRASIL. Ministério da Educação. Secretaria de Educação Média e Tecnológica. Parâmetros Curriculares Nacionais: Ensino Médio. Brasília, 2000.

CÁRCAMO, Silvia. Debates de la actualidad: literatura y formación de profesores. Abehache, São Paulo, v. 1, n. 4, p. 73-85, 2013.

COSSON, Rildo. Letramento literário: teoria e prática. 2. ed. São Paulo:Contexto, 2006.144p.

COSSON, Rildo. Círculos de leitura e letramento literário. São Paulo:Contexto, 2014.192 p.

CRUZ, Maria de Fátima Berenice da. Leitura literária na escola: desafios e perspectivas em um leitor. Salvador: EDUNEB, 2012. 228 p.

FREIRE, Paulo. A importância do ato de ler: em três artigos que se completam. São Paulo: Cortez, 1996.

FREITAS, Vera Aparecida de Lucas. Mediação: estratégia facilitadora da compreensão leitora. In: BORTONI-RICARDO, Stella Maris et al. (org.). Leitura e mediação pedagógica. São Paulo: Parábola, 2012, p. 65-85.

GONÇALVES, Frank da Silva. A literatura nas diversas metodologias de ensino de LE. Caminhos em Linguística Aplicada, Taubaté, v. 4, n. 1, p. 34-51, 2011. Disponível em: www.unitau.br/caminhosla. Acesso em: 21 out. 2019.

KAPLAN, Abraham. A conduta na pesquisa: metodologia para as ciências do comportamento. São Paulo: Herder, 1972

MENDOZA, A. F. Materiales literários en el aprendizaje de lengua extranjera. In: Cuadernos de Educación 55. Barcelona: Horsori Editorial, S. L., 2007. 140 p.

MENDOZA, A. F. La educación literaria: bases para la formación de la competencia lectoliteraria. Málaga: Aljibe, 2004. 242 p.

MENDOZA, A. F. El proceso lector: la interación entre competencias y experiencias lectoras. (Org). La seducción de la lectura en edades tempranas. Ministerio de Educación, Cultura y Deporte. Barcelona, 2002, p. 101-137.

MUNIZ, Camila; CAVALCANTE, Ilane. O lugar da literatura no ensino e espanhol como língua estrangeira. In: CONGIC, VI, 2009, Natal. Anais [...] Natal: IFRN, Holos, 2009. V. 4, p. 48-56.

PAULINO, Graça; COSSON, Rildo. Letramento literário: para viver a literatura dentro e fora da escola. In: ZILBERMAN, Regina; RÖSING, Tania (Org). Escola e leitura: velha crise; novas alternativas. São Paulo: Global, 2009.

SANTOS, A. C. El texto literario y sus funciones en la clase de E/LE de la teoría a la práctica. In: Anuario brasileño de estudios hispánicos, n.1. Embajada de España en Brasil. Madrid: Consejería de educación. P. 33-45, 2007.

SILVA, Ezequiel Teodoro da. Elementos de pedagogia da leitura. São Paulo: Martins Fontes, 2002. 159 p. 
SILVA, Flávia Mathias. Dos PCN LE às OCEM: o ensino de língua inglesa e as políticas linguísticas educativas brasileiras. Pesquisas em Discurso Pedagógico, [s.l.], v. 2015, n. 1, p. 1-18. Disponível em: http://www.maxwell.vrac.puc-rio.br/24801/24801.PDF. Acesso em: 30 out. 2019.

SILVA, Girlene Moreira da. Literatura, leitura e escola: um estudo sobre o desenvolvimento de habilidades de compreensão leitora e da competência literária de alunos de língua espanhola do ensino médio de uma escola pública. Tese (Doutorado em Linguística Aplicada). Universidade Estadual do Ceará, Centro de Humanidades, Fortaleza, 2016.

SILVA, Girlene Moreira da. O uso do texto literário nas aulas de Espanhol no ensino médio de escolas públicas de Fortaleza: relação entre as crenças e a prática docente de egressos da UECE. Dissertação (Mestrado Acadêmico em Linguística Aplicada) Universidade Estadual do Ceará, Centro de Humanidades, Fortaleza, 2011.

SILVA, Girlene Moreira da; ARAGÃO, Cleudene de Oliveira. A leitura literária no ensino comunicativo da língua espanhola no ensino médio. Revista Desenredo, Passo Fundo, v. 9 , n. 1, p.157-173, 9 out. 2013.

SOLÉ, Isabel. Estratégias de leitura. Porto Alegre: Artmed,1998.

SOUZA, Renata Junqueira de; COSSON, Rildo. Letramento literário: uma proposta para a sala de aula. UNESP, Agosto-2011. Disponível em: http://www.acervodigital.unesp.br/bitstream/123456789/40143/1/01d16t08.pdf. Acesso em: 07 out. 2019.

TODOROV, Tzvetan, A Literatura em Perigo, Rio de Janeiro: Difel, 2008. 98 p.

Autores

Mariana Carla Augusto de Lima marianacarla.lima@live.com https://orcid.org/0000-0002-7113-9291

Instituto Federal de Educação, Ciência e Tecnologia do Rio Grande do Norte (IFRN)

Natal, Brasil

Girlene Moreira da Silva

Doutora em Linguística Aplicada

Professora do Curso de Licenciatura em Letras Espanhol do Campus Natal Central do IFRN

Pesquisas na área de Linguística Aplicada, atuando principalmente nos seguintes temas: formação de professores de línguas, crenças, ensino de espanhol como língua estrangeira, ensino de leitura e tratamento didático do texto literário no ensino de línguas estrangeiras.

girlene.moreira@ifrn.edu.br 